BUDGETING : Journal of Business, Management and Accounting

Volume 2, Nomor 1, Desember 2020

e-ISSN: 2715-2480

p-ISSN: 2715-1913

DOI : https://doi.org/10.31539/budgeting.v2i1.1741

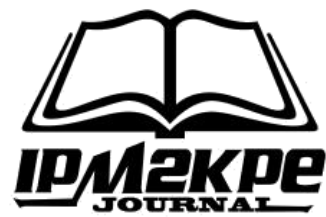

\title{
KEPUTUSAN PEMBELIAN BERDASARKAN COMMERCIAL ADVERTISING
}

\author{
Muhammad Fauzan Mujahidy', Acep Samsudin ${ }^{2}$, Kokom Komariah ${ }^{3}$ \\ Universitas Muhammadiyah Sukabumi ${ }^{1,2,3}$ \\ fauzanmillenix@gmail.com ${ }^{1}$
}

\begin{abstract}
ABSTRAK
Tujuan penelitian ini adalah untuk menganalisis efektifitas pengaruh commercial advertising terhadap keputusan pembelian pada CV. Next Chapter Indonesia Kabupaten Bandung. Metode yang digunakan dalam penelitian ini adalah simple random sampling dengan melakukan penyebaran kuesioner kepada 188 konsumen. Hasil penelitian menunjukkan bahwa nilai uji simultan iklan strategis dan taktis terhadap keputusan pembelian adalah 250,995 dengan signifikansi sebesar 0,000. Simpulan, secara parsial variabel commercial advertising yang di dalamnya terdapat iklan strategis dan iklan taktis menunjukkan adanya berpengaruh positif dan signifikan terhadap keputusan pembelian pada penjualan produk CV. Next Capter Indonesia. Adapun secara simultan, iklan strategis dan iklan taktis berpengaruh signifikan secara bersama-sama (simultan) terhadap keputusan pembelian pada penjualan produk CV. Next Capter Indonesia.
\end{abstract}

Kata Kunci: Commercial Advertising, Keputusan Pembelian

\begin{abstract}
The purpose of this study was to analyze the effectiveness of the effect of commercial advertising on purchasing decisions at CV. Next Chapter Indonesia Bandung Regency. The method used in this research is simple random sampling by distributing questionnaires to 188 consumers. The results showed that the value of strategic and tactical advertising simultaneous test on purchasing decisions was 250.995 with a significance of 0.000. In conclusion, partially the commercial advertising variable in which there are strategic advertising and tactical advertising shows that there is a positive and significant effect on purchasing decisions on the sales of CV products. Next Capter Indonesia. Meanwhile, simultaneously, strategic advertising and tactical advertising have a significant effect together (simultaneously) on purchasing decisions on product sales $C V$. Next Capter Indonesia.
\end{abstract}

Keywords: Commercial Advertising, Purchase Decision

\section{PENDAHULUAN}

Semakin maraknya industri kreatif dalam bidang fashion tentu saja akan menimbulkan persaingan yang sangat ketat. Hal ini mengharuskan para pelaku industri kreatif di bidang fashion untuk memperhatikan faktor-faktor yang akan mempengaruhi atau yang dapat terus membuat pelaku usaha dapat bertahan, berkembang dan tumbuh. 
Dalam hal ini, para pelaku usaha industri kreatif di bidang fashion harus bergerak lebih cepat dalam menarik para konsumennya. Pelaku usaha juga perlu mencermati perilaku dan faktor-faktor yang mempengaruhi keputusan pembelian konsumennya.

Keputusan pembelian secara tidak langsung akan meningkatkan perkembangan kegiatan jual beli. Hal tersebut memicu banyaknya produk produk baru yang bermunculan. Konsumen dibuat senang karena kemudahan dan banyaknya variasi dari produk dalam memenuhi kebutuhan. Namun hal tersebut juga dapat membuat konsumen kebingungan untuk menentukan produk yang akan dipilih. Saat konsumen bingung, disinilah para produsen saling berlomba-lomba merebut perhatian konsumen dengan memberitahukan atau menginformasikan dan menawarkan produknya agar dapat memenangkan persaingan tersebut. Dalam proses tersebut, sisi iklan hadir dalam rangka memenuhi kebutuhan dan memenangkan persaingan menghadapi dominasi memperebutkan konsumen.

Suatu bentuk informasi produk dari produsen yang baik kepada konsumen merupakan tugas dari iklan. Oleh karena itu sebagai salah satu bentuk dari pesan yang akan disampaikan kepada konsumen, informasi harus jelas dan padat. Dengan adanya iklan, diharapkan konsumen dapat memperoleh informasi tentang produk tersebut. Periklanan memang sangat erat kaitannya dengan industri dan perekonomian karna suatu iklan akan sangat mendongkrak tingkat penjualan suatu produk yang akan membuat industri terus bertahan dan berlangsung. Secara tidak langsung akan mengubah tingkat perekonomian di negara Indonesia. Hal tersebutlah yang menjadi cikal bakal dikit banyaknya penggerak perekonomian.

Iklan sebaiknya ditargetkan agar mampu mengenai sasaran yang tepat secara spesifik. Walaupun tujuan akhir dari periklanan adalah untuk mencapai keputusan pembelian dari konsumen, para produsen harus memiliki strategi yang dibuat demi mendongkrak pembelian secara berkala maupun terus menerus. Salah satu strategi tersebut adalah commercial advertising. Peneliti menggunakan strategi promosi iklan commercial advertising untuk mendongkrak keputusan pembelian. Iklan sering digunakan sebagai sarana penyampaian informasi kepada konsumen yang dapat mencapai target audience yang biasanya digunakan sebagai salah satu langkah kegiatan dari promosi. 
Berdasarkan pemaparan di atas, peneliti tertarik untuk menganalisis fenomena yang berkaitan dengan keputusan pembelian. Salah satu perusahaan yang cukup menarik perhatian peneliti adalah CV. Next Chapter Indonesia Kabupaten Bandung. Perusahaan ini melakukan penempatan iklan yang tidak strategis atau tidak sesuai dengan tempat dan waktu, maka sasaran yang menjadi incaran oleh publisher akan meleset jauh dan memperburuk kualitas dan makna dari iklan.

\section{KAJIAN TEORI}

\section{Commercial Advertising}

Menurut Nuraeni (2009) iklan komersial adalah iklan yang bertujuan untuk mendukung kampanye pemasaran suatu produk atau jasa. Iklan komersial ini terbagi menjadi beberapa macam, yaitu: a) iklan strategis, digunakan untuk membangun merek. Hal ini dilakukan dengan mengkomunikasikan nilai merek dan manfaat produk. Perhatian utama dalam jangka panjang adalah mempromosikan merek serta membangun pangsa pikiran dan pangsa pasar. Iklan ini mengundang konsumen untuk menikmati hubungan dengan merek serta meyakinkan bahwa merek ini ada bagi para pengguna; b) iklan taktis, digunakan dikala memiliki tujuan mendesak. Iklan ini dirancang untuk mendorong konsumen agar segera melakukan kontak dengan merek tertentu. Pada umumnya iklan ini memberikan penawaran khusus jangka pendek yang mengacu konsumen memberikan respon pada hari yang sama.

\section{Keputusan Pembelian}

Keputusan pembelian merupakan serangkaian proses yang berawal dari konsumen mengenal masalah, mencari informasi dan mengevaluasi tentang produk atau merek tertentu serta seberapa baik masing-masing alternatif tersebut dapat memecahkan masalahnya dan mengarah kepada keputusan pembelian (Tjiptono, 2014). Kotler \& Keller (2016) menambahkan bahwa proses keputusan pembelian adalah proses lima tahap yang dilewati konsumen, dimulai dari pengenalan masalah, pencarian informasi, evaluasi alternatif yang dapat memecahkan masalahnya, keputusan pembelian dan perilaku pasca pembelian yang dimulai jauh sebelum pembelian yang sesungguhnya dilakukan oleh konsumen dan memiliki dampak yang lama setelah itu. 
Menurut Kurniawan (2016) keputusan pembelian memiliki enam dimensi yang terdiri dari: 1) pilihan produk, dalam hal ini perusahaan harus memusatkan perhatiannya kepada orang-orang yang berniat membeli sebuah produk serta alternatifnya yang mereka pertimbangkan; 2) pilihan merek, konsumen harus menjatuhkan pilihan pada merek apa yang akan dibeli. dalam hal ini perusahaan harus mengetahui bagai mana cara konsumen menjatuhkan pilihan terhadap sebuah merek diantarnanya etertarikan pada merek, kebiasaaan pada merek, kesesuaian harga; 3) pilihan penyalur, konsumen harus menentukan penyalur mana yang akan dipilih untuk membeli produk. dalam hal ini konsumen memilih penyalur dapat dikarekanan faktor lokasi terdekat, harga yang murah, tersedianya barang yang lengkap dan kenyamanan pada saat membeli.

Selanjutnya, 4) jumlah pembelian, konsumen dapat menentukan kuantitas barang yang akan dibeli. dalam hal ini perusahaan harus mempersiapkan banyaknya produk yang sesuai dengan keinginan onsumen yang berbeda-beda karena konsumen akan menentukan keputusan jumlah pembelian, keputusan pembelian untuk persediaan; 5) waktu pembelian, konsumen menentukan waktu pembelian berdasarkan kesesuaian dengan kebutuhan, keuntungan yang dirasakan dan alasan pembelian; 6) metode pembayaran, konsumen dapat menentukan metode pembayaran yang akan digunakan pada saat transaksi pembelian. Konsumen dapat menggunakan cara pembayaran tunai, cek, kartu kredit, kartu debit, kartu ATM, kredit melalui lembaga keuangan dan kredit melalui toko.

\section{METODE PENELITIAN}

Penelitian ini dilaksanakan di CV. Next Chapter Indonesia Kabupaten Bandung. Penelitian dilakukan dengan menggunakan pendekatan manajemen pemasaran, khususnya tentang efektivitas commercial advertising terhadap keputusan pembelian. Populasi dalam penelitian ini adalah konsumen perusahaan CV. Next Chapter Indonesia. Metode yang digunakan adalah probability sampling dengan metode pendekatan simple random sampling. Peneliti melakukan penyebaran kuesioner sebanyak 100 responden. 


\section{HASIL PENELITIAN}

Uji Validitas

Tabel 1.

Iklan Strategis

\begin{tabular}{cccc}
\hline No. Item & r-Hitung & r-Kritis & Keputusan \\
\hline 1 & 0,771 & 0,3 & Valid \\
2 & 0,871 & 0,3 & Valid \\
3 & 0,814 & 0,3 & Valid \\
4 & 0,807 & 0,3 & Valid \\
5 & 0,628 & 0,3 & Valid \\
6 & 0,771 & 0,3 & Valid \\
7 & 0,846 & 0,3 & Valid \\
8 & 0,814 & 0,3 & Valid \\
9 & 0,807 & 0,3 & Valid \\
\hline
\end{tabular}

(Sumber: Hasil Pengolahan Data, 2019)

Umumnya syarat minimum agar dapat memenuhi syarat validitas adalah $r=0,3$. Dengan demikian hasil uji validitas iklan strategis pada tabel 1 dinyatakan positif.

Tabel 2.

Iklan Taktis

\begin{tabular}{cccc}
\hline No. Item & r-Hitung & r-Kritis & Keputusan \\
\hline 1 & 0,876 & 0,3 & Valid \\
2 & 0,761 & 0,3 & Valid \\
3 & 0,763 & 0,3 & Valid \\
4 & 0,876 & 0,3 & Valid \\
\hline
\end{tabular}

(Sumber: Hasil Pengolahan Data, 2019)

Tabel 3.

Keputusan Pembelian

\begin{tabular}{cccc}
\hline No. Item & r Hitung & r Kritis & Keputusan \\
\hline 1 & 0,479 & 0,3 & Valid \\
2 & 0,758 & 0,3 & Valid \\
3 & 0,634 & 0,3 & Valid \\
4 & 0,666 & 0,3 & Valid \\
\hline 5 & 0,553 & 0,3 & Valid \\
6 & 0,528 & 0,3 & Valid \\
7 & 0,471 & 0,3 & Valid \\
8 & 0,739 & 0,3 & Valid \\
\hline 9 & 0,654 & 0,3 & Valid \\
10 & 0,785 & 0,3 & Valid \\
11 & 0,566 & 0,3 & Valid \\
12 & 0,756 & 0,3 & Valid \\
13 & 0,486 & 0,3 & Valid \\
14 & 0,751 & 0,3 &
\end{tabular}

(Sumber: Hasil Pengolahan Data, 2019) 
Berdasarkan hasil analisis pada tabel 3, item yang memiliki nilai validitas tertinggi yaitu item nomor satu dan sepuluh dengan nilai koefisien korelasi sebesar 0,785 sedangkan item yang memiliki nilai validitas terendah yaitu terdapat pada item nomor tujuh dengan nilai koesfisien korelasi sebesar 0,471. Artinya item penelitian dapat digunakan pada analisis data berikutnya.

Tabel 4.

Hasil Uji Reliabilitas Item Variabel Iklan Strategis

\begin{tabular}{cc}
\hline \multicolumn{2}{c}{ Reliability Statistics } \\
\hline Cronbach's Alpha & Nof Items \\
\hline, 923 & 9
\end{tabular}

(Sumber: Hasil Pengolahan Data, 2019)

Tabel 5.

Hasil Uji Reliabilitas Item Variabel Iklan Taktis

\begin{tabular}{cc}
\hline \multicolumn{2}{c}{ Reliability Statistics } \\
\hline Cronbach's Alpha & Nof Items \\
\hline, 829 & 4 \\
\hline
\end{tabular}

(Sumber: Hasil Pengolahan Data, 2019)

Tabel 6.

Hasil Uji Reliabilitas Item Variabel Keputusan Pembelian

\begin{tabular}{ccc}
\hline \multicolumn{2}{c}{ Reliability Statistics } \\
\hline Cronbach's Alpha & Nof Items \\
\hline, 872 & 14 \\
\hline
\end{tabular}

(Sumber: Hasil Pengolahan Data, 2019)

Berdasaran uji reliabilitas, hasil pengujian iklan strategis menunjukkan nilai sebesar 0,923, iklan taktis sebesar 0,829. Adapun hasil keputusan pembelian adalah sebesar 0,872. Skor tersebut berada di atas r-kritis 0,6 sehingga dapat dikatakan reliable. Artinya item penelitian dapat digunakan pada analisis data berikutnya.

\section{Pengujian Korelasi Antar Sub Variabel Secara Parsial}

\section{Korelasi antar Variabel Iklan Strategis (X1) dan Iklan Taktis (X2)}

Nilai korelasi antar subvariabel dihitung dengan korelasi Pearson (Product Momment) dengan rumus sebagai berikut:

$$
\mathrm{r}_{\mathrm{yx}}=\frac{n \sum \mathrm{XY}-\left(\sum \mathrm{X}\right)\left(\sum \mathrm{Y}\right)}{\sqrt{\left[n \mathrm{X}^{2}-\left(\sum \mathrm{X}\right)^{2}\right]\left[n \mathrm{Y}^{2}-\left(\sum \mathrm{Y}\right)^{2}\right]}}
$$


Tabel 7.

Hasil Korelasi antara X1 dan X2

\begin{tabular}{llcc}
\hline & \multicolumn{1}{c}{ Correlations } & \\
\hline & & Iklan Strategis & Iklan Taktis \\
\hline Iklan Strategis & \multicolumn{1}{c}{ Pearson Correlation } & 1 &, $682^{* * *}$ \\
\cline { 2 - 4 } & Sig. (2-Tailed) & 100 &, 000 \\
\cline { 2 - 4 } & $\mathrm{N}$ &, $682^{* *}$ & 100 \\
\hline \multirow{2}{*}{ Iklan Taktis } & Pearson Correlation &, 000 & 1 \\
\cline { 2 - 4 } & Sig. (2-Tailed) & 100 & 100 \\
\cline { 2 - 4 } & $\mathrm{N}$ & & \\
\hline
\end{tabular}

*. Correlation is Significant at the 0.01 Level (2-Tailed)

(Sumber: Hasil Pengolahan Data, 2019)

Hasil analisis pada tabel 7 menunjukkan bahwa perhitungan korelasi menghasilkan nilai sebesar 0,682. Hal tersebut membuktikan bahwa antara X1 dan X2 memiliki tingkat hubungan yang kuat.

\section{Korelasi Antar Variabel Iklan Strategis (X1) terhadap Keputusan Pembelian (Y)}

Tabel 8.

Hasil Korelasi antara X1 terhadap Y

\begin{tabular}{|c|c|c|c|}
\hline \multicolumn{4}{|c|}{ Correlations } \\
\hline & & Iklan Strategis & Keputusan Pembelian \\
\hline \multirow[t]{3}{*}{ Iklan Strategis } & Pearson Correlation & 1 &, $842^{* *}$ \\
\hline & Sig. (2-Tailed) & &, 000 \\
\hline & $\mathrm{N}$ & 100 & 100 \\
\hline \multirow[t]{3}{*}{ Keputusan Pembelian } & Pearson Correlation &, $842^{* *}$ & 1 \\
\hline & Sig. (2-Tailed) & ,000 & \\
\hline & $\mathrm{N}$ & 100 & 100 \\
\hline
\end{tabular}

**. Correlation Is Significant at the 0.01 Level (2-Tailed)

(Sumber: Hasil Pengolahan Data, 2019)

Hasil analisis pada tabel 8 menunjukkan bahwa perhitungan korelasi menghasilkan nilai sebesar 0,842. Hal tersebut bermakna bahwa antara X1 dan Y memiliki tingkat hubungan yang sangat kuat.

\section{Korelasi Antar Variabel Iklan Taktis (X2) Terhadap Keputusan Pembelian (Y)}

Tabel 9.

Hasil Korelasi antara X2 terhadap Y

\begin{tabular}{llcc}
\hline \multicolumn{2}{c}{ Correlations } & \\
\hline & & Iklan Taktis & Keputusan Pembelian \\
\hline \multirow{2}{*}{ Iklan Taktis } & \multicolumn{1}{c}{ Pearson Correlation } & 1 &, $837^{* * *}$ \\
\cline { 2 - 4 } & Sig. (2-Tailed) & 100 &, 000 \\
\cline { 2 - 3 } & $\mathrm{N}$ & 100 \\
\hline
\end{tabular}




\begin{tabular}{|c|c|c|c|}
\hline \multirow[t]{3}{*}{ Keputusan Pembelian } & Pearson Correlation &, $837^{* * *}$ & 1 \\
\hline & Sig. (2-Tailed) &, 000 & \\
\hline & $\mathrm{N}$ & 100 & 100 \\
\hline
\end{tabular}

(Sumber: Hasil Pengolahan Data, 2019)

Berdasarkan kriteria Guillford, hasil perhitungan korelasi pada tabel 9 menunjukkan nilai sebesar 0,837. Artinya antara X2 dan Y memiliki tingkat hubungan yang sangat kuat.

Tabel 10.

Matrik Korelasi antar Variabel

\begin{tabular}{cccc}
\hline & $\mathbf{X 1}$ & $\mathbf{X 2}$ & $\mathbf{Y}$ \\
\hline $\mathbf{X 1}$ & 1,00 & 0,682 & 0,842 \\
\hline $\mathbf{X 2}$ & 0,682 & 1,00 & 0,837 \\
\hline $\mathbf{Y}$ & 0,842 & 0,837 & 1,00 \\
\hline
\end{tabular}

(Sumber: Hasil Pengolahan Data, 2019)

\section{Koefisien Jalur}

Tabel 11.

Koefisien Jalur Iklan Strategis (X1) dan Iklan Taktis (X2)

Coefficients $^{a}$

\begin{tabular}{|c|c|c|c|c|c|c|}
\hline \multicolumn{7}{|c|}{ Coefficients $^{a}$} \\
\hline & & \multicolumn{2}{|c|}{ Unstandardized Coefficients } & \multirow{2}{*}{ Standardized Coefficients } & \multirow[b]{2}{*}{$\mathbf{t}$} & \multirow[b]{2}{*}{ Sig. } \\
\hline \multicolumn{2}{|c|}{ Model } & B & Std. Error & & & \\
\hline 1 & (Constant) & 7,482 & 2,364 & & 3,164 &, 002 \\
\hline & $\mathrm{X} 1$ & ,643 & ,071 & ,508 & 9,088 & ,000 \\
\hline & $\mathrm{X} 2$ & 1,478 & ,169 & ,490 & 8,768 & 000 \\
\hline
\end{tabular}

a. Dependent Variable: Y

(Sumber: Hasil Pengolahan Data, 2019)

Koefisien jalur dimensi iklan strategis dan iklan taktis masing-masing adalah sebesar 0,598 dan 0,490. Nilai tersebut merupakan bobot nilai untuk pengaruh langsung dimensi iklan strategis dan taktis terhadap keputusan pembelian.

\section{Koefisien Determinasi Iklan Strategis (X1) terhadap Keputusan Pembelian (Y)}

Berikut merupakan perhitungan koefisien determinasi iklan strategis (X1) terhadap keputusan pembelian $(\mathrm{Y})$ :

$$
\begin{array}{ll}
\mathrm{r} & =0,842 \\
\mathrm{Kd} & =(0,842443)^{2} \times 100 \% \\
\mathrm{Kd} & =70,9 \%
\end{array}
$$




\section{Koefisien Determinasi Iklan Taktis (X2) terhadap Keputusan Pembelian (Y)}

Berikut merupakan perhitungan koefisien determinasi iklan taktis (X2) terhadap keputusan pembelian (Y):

$$
\begin{aligned}
\mathrm{r} & =0,837 \\
\mathrm{Kd} & =(0,837)^{2} \times 100 \% \\
\mathrm{Kd} & =70,0 \%
\end{aligned}
$$

\section{Penghitungan Variabel Lain Iklan Strategis (X1) terhadap Keputusan Pembelian} (Y)

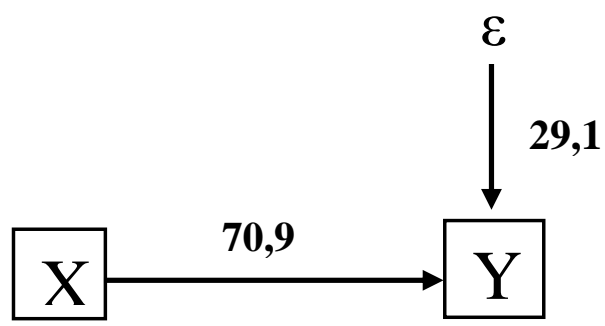

Gambar 1.

Paradigma Hasil Penelitian Variabel Lain Iklan Strategis (X1) terhadap Keputusan Pembelian (Y)

\section{Pengujian Variabel Iklan Strategis (X1) dan Iklan Taktis (X2) terhadap Variabel Keputusan Pembelian (Y) Berdasarkan Koefisien Korelasi}

Tabel 12.

Koefisien Korelasi Menurut Kriteria Guilford Iklan Strategis (X1) dan Iklan Taktis (X2) terhadap Keputusan Pembelian (Y)

\begin{tabular}{|c|c|c|c|c|}
\hline \multicolumn{5}{|c|}{ Model Summary } \\
\hline Model & R & R Square & Adjusted R Square & Std. Error of the Estimate \\
\hline 1 &, $915^{\text {a }}$ &, 838 &, 835 & 2,38383 \\
\hline a. Predictors: (Constant), Iklan Taktis, Iklan Strategis \\
\hline
\end{tabular}
(Sumber: Hasil Pengolahan Data, 2019)

Berdasarkan perhitungan tabel 12, dapat diketahui bahwa korelasi variabel iklan strategis dan iklan taktis adalah sebesar 0,915. Hasil penghitungan korelasi menghasilkan nilai sebesar 0,915 dengan drajat kepercayan 90\% dengan kekeliluruan $10 \%$ atau $\alpha=0,1$. Berdasarkan hal tersebut, maka nilai yang diperoleh terletak pada keriteria korelasi atau hubungan yang sangat kuat. 


\section{Koefisien Determinasi}

Berikut merupakan perhitungan koefisien determinasi iklan strategis (X1) dan iklan taktis X2 terhadap Variabel Keputusan Pembelian (Y):

$$
\begin{aligned}
\mathrm{r} & =0,915 \\
\mathrm{Kd} & =(0,915)^{2} \times 100 \% \\
\mathrm{Kd} & =83,7 \%
\end{aligned}
$$

\section{Pengaruh Variabel Lain}

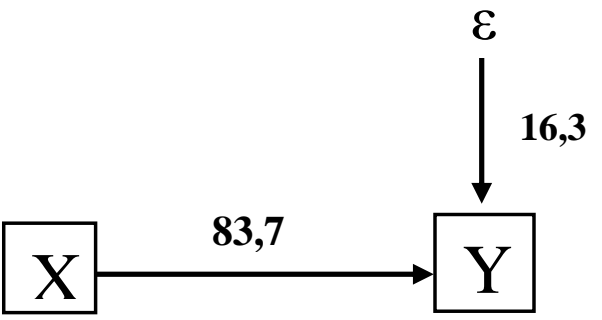

Gambar 2.

Paradigma Hasil Penelitian Pengaruh Iklan Strategis (X1) dan Iklan Taktis (X2) terhadap Keputusan Pembelian (Y)

\section{Menghitung Regresi Linier Berganda}

\begin{tabular}{|c|c|c|c|c|c|c|}
\hline \multicolumn{7}{|c|}{ Coefficients $^{a}$} \\
\hline & \multirow[b]{2}{*}{ Model } & \multicolumn{2}{|c|}{ Unstandardized Coefficients } & \multirow{2}{*}{$\begin{array}{c}\begin{array}{c}\text { Standardized } \\
\text { Coefficients }\end{array} \\
\text { Beta }\end{array}$} & \multirow[b]{2}{*}{$\mathbf{t}$} & \multirow[b]{2}{*}{ Sig. } \\
\hline & & $\mathbf{B}$ & Std. Error & & & \\
\hline \multirow[t]{3}{*}{1} & $($ Constant $)$ & 7,482 & 2,364 & & 3,164 &, 002 \\
\hline & Iklan Strategis &, 643 &, 071 & ,508 & 9,088 &, 000 \\
\hline & Iklan Taktis & 1,478 & , 169 & ,490 & 8,768 &, 000 \\
\hline
\end{tabular}

Tabel 13.

Hasil Perhitungan Regresi Linear Berganda

a. Dependent Variable: Keputusan Pembelian

(Sumber: Hasil Pengolahan Data, 2019)

Berdasarkan tabel 13, maka dapat diketahui nilai dari persamaan regresi linier berganda tersebut, adalah sebagai berikut:
$\mathrm{a} \quad=7,482$
b1 $=0,643$
$\mathrm{b} 2=1,478$ 
Selanjutnya didapat persamaan regresi linier berganda untuk iklan strategis dan iklan taktis adalah:

$$
Y^{*}=7,482+0,643 \times 1+1,478 \times 2
$$

Berdasarkan persamaan tersebut, diketahui bahwa terdapat pengaruh positif antara variabel X1dan X2 terhadap variabel Y. Hal ini bermakna bahwa keputusan pembelian akan meningkat jika peran iklan strategis dan iklan taktis ditingkatkan terhadap keputusan pembelian.

\section{Pengaruh Langsung}

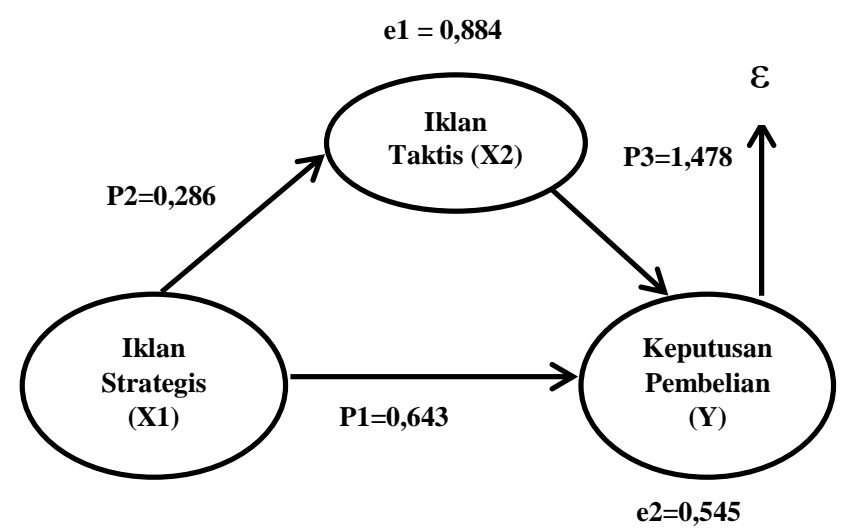

Gambar 3.

Pengaruh Langsung

Berdasarkan hasil analisis dapat disimpulkan bahwa variabel iklan strategis (X1) berpengaruh langsung terhadap X2 dan Y. Adapun besarnya pengaruh langsung X1 terhadap Y adalah sebesar 0,643.

\section{Pengaruh Tidak Langsung}

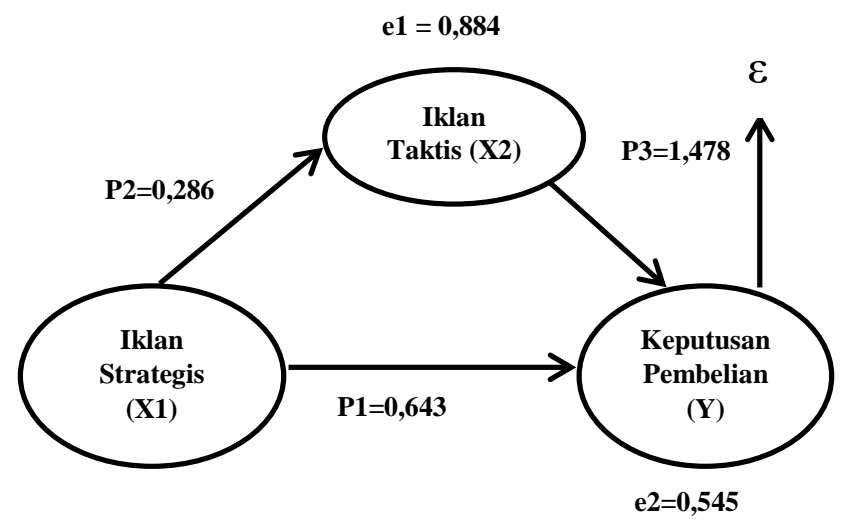

Gambar 4.

Pengaruh Tidak Langsung 
Berdasarkan gambar 4, diketahui bahwa variabel iklan strategis (X1) berpengaruh tidak langsung terhadap keputusan pembelian (Y) melalui variabel iklan taktis (X2) dengan menghitung besaran pengaruh tidak langsung menggunakan rumus:

$$
\begin{aligned}
& =\mathrm{P} 2 \times \mathrm{P} 3 \\
& =0,286 \times 1,478 \\
& =442,708
\end{aligned}
$$

\section{Total Pengaruh Variabel X1 dan X2 terhadap Y}

Berikut hasil perhitungan pengaruh total antara variabel $\mathrm{X} 1$ dan $\mathrm{X} 2$ terhadap $\mathrm{Y}$ :

$$
\begin{gathered}
\mathrm{P} 1+(\mathrm{P} 2 \times \mathrm{P} 3)=0,643+442,708 \\
=443,351
\end{gathered}
$$

Jadi total besarnya pengaruh variabel $\mathrm{X}$ terhadap $\mathrm{Y}$ berdasarkan perhitungan analisis di atas adalah sebesar 443,351.

\section{Pengujian Hipotesis Secara Simultan (Bersama)}

Tabel 14.

Hasil Pengujian Uji Pengaruh Simultan (Uji F)

\begin{tabular}{llccccc}
\hline \multicolumn{7}{c}{ ANOVA $^{\mathbf{a}}$} \\
\hline \multirow{2}{*}{1} & Model & Sum of Squares & df & Mean Square & F & Sig. \\
\cline { 2 - 7 } & Regression & 2852,625 & 2 & 1426,312 & 250,995 &, $000^{\mathrm{b}}$ \\
\cline { 2 - 7 } & Residual & 551,215 & 97 & 5,683 & & \\
\cline { 2 - 6 } & Total & 3403,840 & 99 & & & \\
\hline
\end{tabular}

a. Dependent Variable: Y

b. Predictors: (Constant), X2, X1

\begin{tabular}{|c|c|c|c|c|c|c|}
\hline \multicolumn{7}{|c|}{ Coefficients $^{a}$} \\
\hline & \multirow[b]{2}{*}{ Model } & \multicolumn{2}{|c|}{ Unstandardized Coefficients } & \multirow{2}{*}{$\frac{\text { Standardized Coefficients }}{\text { Beta }}$} & \multirow[b]{2}{*}{$\mathbf{t}$} & \multirow[b]{2}{*}{ Sig. } \\
\hline & & B & Std. Error & & & \\
\hline \multirow[t]{2}{*}{1} & (Constant) & 6,626 & 1,249 & & 5,307 &, 000 \\
\hline & $\mathrm{X} 1$ & ,286 & ,031 & ,682 & 9,242 &, 000 \\
\hline & endent $\mathrm{Va}$ & & & & & \\
\hline
\end{tabular}

(Sumber: Hasil Pengolahan Data, 2019)

\section{Pengujian Hipotesis Variabel X1 terhadap X2}

Tabel 15.

Hasil Pengujian Hipotesis Variabel X1 terhadap X2 Secara Parsial

(Sumber: Hasil Pengolahan Data, 2019) 


\section{Pengujian Hipotesis Variabel X2 terhadap Y}

Tabel 16.

Hasil pengujian Hipotesis Secara Parsial

\begin{tabular}{|c|c|c|c|c|c|c|}
\hline \multicolumn{7}{|c|}{ Coefficients $^{a}$} \\
\hline \multirow{2}{*}{\multicolumn{2}{|c|}{ Model }} & \multicolumn{2}{|c|}{ Unstandardized Coefficients } & \multirow{2}{*}{$\frac{\text { Standardized Coefficients }}{\text { Beta }}$} & \multirow{2}{*}{$\mathbf{t}$} & \multirow{2}{*}{ Sig. } \\
\hline & & B & Std. Error & & & \\
\hline \multirow{2}{*}{1} & (Constant) & 14,305 & 3,035 & & 4,713 & ,000 \\
\hline & $\mathrm{X} 2$ & 2,524 &, 167 & ,837 & 15,128 &, 000 \\
\hline
\end{tabular}

(Sumber: Hasil Pengolahan Data, 2019)

\section{Hasil Uji Hipotesis Variabel Mediasi}

Pengujian hipotesis mediasi dapat dilakukan dengan prosedur uji Sobel (Sobel test). Pengujian ini dapat dihitung dengan rumus dibawah ini:

$$
\begin{aligned}
\text { e1 } & =\sqrt{1-r^{2}} \\
& =\sqrt{1-0,21756} \\
& =\sqrt{0,78244} \\
& =0,884556386 \\
& =0,884 \\
& =\sqrt{1-r^{2}} \\
& =\sqrt{1-0,838^{2}} \\
& =\sqrt{1-0,702244} \\
& =0,5456702301 \\
& =0,545
\end{aligned}
$$

Berdasarkan hasil analisis, dapat diketahui bahwa X1 berpengaruh terhadap Y dan X2 berpengaruh terhadap Y dan dapat juga berpengaruh tidak langsung melalui X2 sebagai mediasi. Besarnya pengaruh langsung adalah 0,643. Adapun besarnya pengaruh tidak langsung dihitung menggunakan rumus sebagai berikut :

$$
\begin{aligned}
\mathbf{P 2} \times \mathbf{P 3} & =0,286 \times 1,478 \\
& =0,422
\end{aligned}
$$

Adapun besarnya pengaruh $\mathrm{X} 1$ terhadap $\mathrm{Y}$ diperoleh berdasarkan rumus berikut:

$$
\begin{aligned}
\mathbf{P 1}+(\mathbf{P 2} \times \mathbf{P 3}) & =0,643+0,422 \\
& =1,065
\end{aligned}
$$


Pengukuran signifikan atau tidaknya hasil yang diperoleh, maka diuji dengan menggunakan Sobel test dengan rumus sebagai berikut:

$$
\begin{aligned}
& \text { Sp2p3 }=\sqrt{p 3^{2} S p 2^{2}+p 2^{2} S p 3^{2}+S p 2^{2} S p 3^{2}} \\
& =\sqrt{(1,478)^{2}(0,031)^{2}+(0,286)^{2}(0,169)^{2}+(0,031)^{2}(0,169)^{2}} \\
& =\sqrt{(2,184484)(0,000961)+(0,081796)(0,28561)+(0,000961)(0,28561)} \\
& =\sqrt{0,0020992891+0,0233617556+0,0002744712} \\
& =\sqrt{0,0257355159} \\
& =0,160
\end{aligned}
$$

Pengujian signifikansi pengaruh tidak langsung dapat dilakukan dengan menghitung nilai $t$ dari koefisien ab dengan rumus sebagai berikut:

$$
\begin{aligned}
\mathbf{t} \text { hitung } & =\frac{\mathbf{p} 2 \mathbf{p 3}}{\mathbf{s p 2} \mathbf{p 3}} \\
& =\frac{(0,286)(1,478)}{(0,0031)(1,478)} \\
& =\frac{422,708}{0,045818}
\end{aligned}
$$

Koefisien mediasi menunjukkan hasil sebesar 0,422, artinya terdapat pengaruh yang signifikan pada mediasi (variabel X2). Berdasarkan hasil analisis tersebut, maka didapatkan nilai $t_{\text {hitung }}$ sebesar 9.225,800. Adapun nilai $t_{\text {tabel }}$ untuk signifikan $10 \%$ adalah sebesar 1,290, maka 9.225,800 >1,290. Jika nilai $t_{\text {hitung }} \geq t_{\text {tabel }}$, maka dapat di simpulkan bahwa variabel iklan taktis (X2) memiliki pengaruh yang siginifikan dalam memediasi iklan strategis (X1) terhadap keputusan pembelian (Y).

\section{PEMBAHASAN}

Salah satu upaya agar tercapai kesuksesan pemasaran bagi suatu perusahaan adalah dengan memaksimalkan promosinya. Menurut (Sunyoto, 2012), promosi merupakan unsur dalam bauran pemasaran perusahaan yang didayagunakan untuk memberitahu, membujuk dan mengingatkan konsumen tentang produk perusahaan. Menurut Tjiptono \& Diana (2016) periklanan (advertising) adalah segala bentuk presentasi dan promosi gagasan, barang atau jasa yang disajikan oleh sponsor yang 
teridentifikasi. Media periklanan yang digunakan dapat berupa brosur, baliho, sosial media dan radio.

Kwan (2016) menyatakan bahwa terdapat beberapa indikator promosi penjualan, diantaranya yaitu: 1) monetary, yaitu promosi penjualan yang berkaitan dengan uang. Promosi monetary ini berbentuk pemberian potongan harga secara intensif pada konsumen saat melakukan pembelian; 2) nonmonetary, yaitu promosi penjualan yang tidak memiliki kaitan dengan uang atau promosi penjualan yang tidak memberikan intensif secara langsung dan lebih cenderung pada hubungan dengan konsumen.

Terdapat beberapa faktor yang dapat mempengaruhi efektivitas suatu iklan. Hal ini dapat dilihat dari karakteristik iklan dan karakteristik individu. Karakateristik iklan meliputi kualitas pesan iklan dan daya tarik iklan. Iklan yang menarik akan mampu mempengaruhi perilaku konsumen untuk bertindak sesuai dengan tujuan iklan tersebut. Iklan layanan masyarakat yang baik akan membuat penonton mau dan mengaplikasikan pesan yang disampaikan. Karakteristik individu meliputi usia, jenis kelamin, tingkat pendidikan dan budaya kelompok. Penerimaan, pemahaman dan keputusan untuk bertindak sesuai pesan yang disampaikan pada iklan layanan masyarakat akan dipengaruhi oleh interest masing-masing penonton dan dari interaksinya bersama orang lain (Ibtisimah, 2016).

Menurut Riyanto (2008) daya tarik iklan merupakan faktor yang paling penting mempengaruhi efektivitas iklan. Hal tersebut dapat berupa believable, meaningful dan distinctive. Believable bermaksud bahwa suatu iklan hendaknya memperlihatkan proses manfaat produk yaitu perubahan bertahap dari waktu kewaktu dari sebelum memakai dan setelah memakai. Iklan hendaknya juga menampilkan bukti survey konsumen mengenai khasiat dan hasil uji laboratorium. Adapun meaningful bermakna bahwa iklan hendaknya menyampaikan banyak informasi mengenai manfaat produk dan kelebihan produk sehingga bisa membuat orang mempunyai harapan dan impian atas pemakaian produk yang diiklankan. Selanjutnya yaitu distinctive yang merupakan persepsi responden yang mengharapkan suatu iklan dapat menampilkan keunggulan termasuk hasil uji laboratorium farmatologi dengan hasil yang lebih baik dan berbeda dari yang ditampilkan produk pesaing.

Berdasarkan hasil penelitian, commercial advertising berupa iklan strategis dan iklan taktis terbukti menunjukkan adanya pengaruh positif dan signifikan terhadap 
keputusan pembelian pada penjualan produk CV. Next Capter Indonesia. Hal ini sejalan dengan hasil penelitian Haryani (2019) bahwa periklanan dan promosi penjualan secara parsial dan simultan berpengaruh terhadap keputusan pembelian. Hal ini menunjukkan bahwa semakin baik periklanan dan promosi penjualan, maka dapat meningkatkan keputusan pembelian.

\section{SIMPULAN}

Secara parsial variabel commercial advertising yang di dalamnya terdapat iklan strategis dan iklan taktis berpengaruh positif dan signifikan terhadap keputusan pembelian pada penjualan produk CV. Next Capter Indonesia. Adapun berdasarkan hasil uji simultan, variabel iklan strategis dan iklan taktis berpengaruh signifikan secara bersama-sama (simultan) terhadap keputusan pembelian pada penjualan produk $\mathrm{CV}$. Next Capter Indonesia.

\section{DAFTAR PUSTAKA}

Haryani, D. S. (2019). Pengaruh Periklanan dan Promosi Penjualan terhadap Keputusan Pembelian pada Perumahan Griya Puspandari Asri Tanjungpinang. Dimensi, $8(1), 54-70$

Ibtisamah, S. (2016). Efektifitas Iklan Layanan Masyarakat di Televisi dalam Perubahan Pengetahuan, Sikap dan Perilaku. Laporan Studi Pustaka (KPM 403). Isntitut Pertanian Bogor

Kotler, P., \& Keller, K. L. (2016): Marketing Management, 15th Edition. New Jersey: Pearson Pretice Hall, Inc

Kurniawan, B. D. (2016). Hubungan Persuasi SPG terhadap Keputusan Membeli pada Produk Smartphone. Thesis. UIN Sunan Ampel Surabaya

Kwan, O. G. (2016). Pengaruh Sales Promotion dan Store Atmosphere terhadap Impulse Buying dengan Positive Emotion Sebagai Variabel Intervening pada Planet Sports Tunjungan. Jurnal Manajemen Pemasaran, 10(1), 27-34

Nuraeni, N. (2009). Pengantar Periklanan dalam Perspektif Komunikasi dan Pemasaran. Banten: Dinas Pendidikan Provinsi Banten

Riyanto, M. (2008). Analisis Faktor yang Mempengaruhi Efektifitas Iklan dan Implikasinya terhadap Sikap Merk (Studi Kasus pada Iklan Pond di Kota Semarang). Tesis, Universitas Diponegoro

Sunyoto, D. (2012). Dasar-Dasar Manajemen Pemasaran. Yogyakarta: CAPS

Tjiptono, F. (2014). Pemasaran Jasa: Prinsip, Penerapan dan Penelitian. Yogyakarta: Andi Offset

Tjiptono, F., \& Diana, A. (2016). Pemasaran Esensi \& Aplikasi. Yogyakarta: Andi Offset 